\title{
Yes, it's caries again
}

\author{
Stephen Hancocks OBE \\ Editor-in-Chief
}

The BDJ Upfront section includes editorials, letters, news, book reviews and interviews. Please direct your correspondence to the News Editor,

Kate Quinlan at k.quinlan@nature.com. Press releases or articles may be edited, and should include a colour photograph if possible.

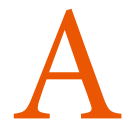

pril seems a long time ago now. Although it is a matter of a mere five months the chasm of experience that we have all crossed in those 20-odd weeks is for many the largest of their lives. Coronavirus has marked 2020 as a year like no other and reset umpteen indices to a spot somewhere behind zero. Back in April my editorial entitled 'Something beginning with c' mentioned caries but didn't explicitly cast it as one of the words on which I was focussing. ${ }^{.}$This time it is.

Looking forward one month we will be publishing our third themed issue on minimum intervention dentistry. It was planned before the virus called corona even existed but has perhaps a relevance greater than any of us could have predicted. The need for prevention and minimal intervention has never been more pertinent and techniques to minimise aerosol generating procedures (AGPs) never more earnestly investigated. Further analysis suggests that the root cause (no pun intended) behind the majority of these AGPs is, yes you've spotted it, caries. We are not exercised by one pesky microorganismassociated condition but by two, making our daily toil more than twice as difficult.

But I think if we push this integration even further we discover yet another fascinating anomaly created by the process of acid on enamel, the creation of the NHS dental service structure itself. We need first to revisit some history, even though I appreciate that it is generally well known it is key to our understanding of some of our current dilemmas. At the outset of the NHS there was an all but overwhelming backlog of caries to deal with. The UK's teeth were in a parlous state of disrepair. The proposal was therefore to incentivise dentists to work as hard and efficiently as possible to improve the nation's oral health by introducing what was in essence a piece-work scheme. This tantalised clinicians with the reward of greater earnings for increased work; not a salaried service as for general medical practitioners but a scheme of independent contractors. Dentists provided everything to complete their tasks; premises, equipment, materials, staff and first and foremost their own labour.

The BDA advised members not to take part. It is not only a matter of debate for historians but for all of us as to whether that was sound advice or not but what is a matter of fact is that the vast majority of dentists ignored it and took the government's shilling. The rest is a matter of history and there are pluses and minuses all the way from the 1950s to COVID time itself. to its limits worked well to reduce the decay burden, improve function, aesthetics and oral health in a way that probably would not have been possible under any other system. But at what cost to the profession and the individual dentists? While admittedly not all of this is caries-based care, the system itself has undeniably been predicated by those original conditions of untreated cavities and this brings us neatly to 2020 , corona, furloughs, business rates and all the other financial horrors. What if. What if the BDA's advice had been heeded all those demineralised surfaces ago? What if we were all salaried

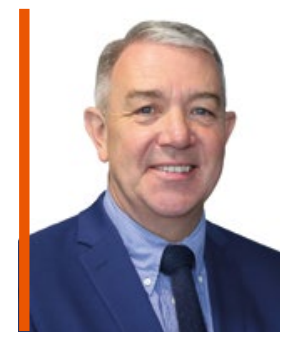

'What if the BDA's advice had been heeded all those demineralised surfaces ago?'

A letter in this issue recounts the eyewitness memories of a dental nurse from those heady post-war days recalling a massive influx of patients seeking dentures to replace their missing teeth. The demand was so high that of the dental team she muses 'we just couldn't keep up. Then, spurred on by the advent of the air rotor, restorative care took over but not before successive governments started and then ratchetted up a two-pronged strategy to moderate the steeply rising costs; the dual slippery slope of reducing fees and implementing ever increasing patient charges. The result of all of this, decades later, was the introduction of units of dental activity (UDAs) which prior to the pandemic had all but ground any progress in NHS dentistry to a halt in England at least.

On the plus side, one can claim that the entrepreneurial spirit that drove the service clinicians akin to our GP colleagues? Would the likes of this pandemic have affected us so badly? Would fallow times have presented such a headache?

If we look forward now, rather than backwards, are there lessons we can apply to the dental practices we want for the rest of this century and beyond based not just on the impetus to mop up existing caries but to take the opportunity to base them on real prevention? I hoped in my previous editorial that one of the words beginning with ' $c$ ' might be co-operation and to some extent, through redeployment and many other acts of kindness, that came true. Another might be contract reform. Perhaps corona has presented us with the chance to change.

\section{References}

1. Hancocks S. Something beginning with ' $c$ '. Br Dent J 2020; 228: 485 